\title{
COOPERAÇÃO, SOBERANIA E DEFESA: MARINHA MERCANTE BRASILEIRA NO FORTALECIMENTO LÓGISTICO DO SISGAAZ E DEFESA DA SOBERANIA DA AMAZÔNIA AZUL
}

\author{
Messias Bezerra da Silva Neto \\ Centro de Instrução Almirante Braz de Aguiar, Belém, Pará \\ messiasbezerra@hotmail.com \\ Ivan Gabriel Ferreira Lima \\ Centro de Instrução Almirante Braz de Aguiar, Belém, Pará \\ ivangabrielflima@gmail.com \\ Helena Lucia Damasceno Ferreira \\ Universidade Federal do Pará, Belém, Pará \\ helenaluciaferreira@yahoo.com.br
}

\begin{abstract}
Resumo
A Amazônia Azul é uma importante área sob a responsabilidade do Brasil, nela estão importantes reservas de recursos naturais. No contexto geopolítico atual, desenvolvem-se ameaças ao exercício da soberania e jurisdição. Nesse sentido, a Marinha do Brasil desenvolveu e está implantando o SisGAAZ, que pode ter maior eficiência e eficácia com os navios da Marinha Mercante Nacional, a qual intensifica a presença brasileira nessa região, permitindo além da imposição da soberania, por meio da exploração e presença, também incrementando os fluxos de informação para maior precisão e concentração dos recursos navais disponíveis para defesa e manutenção da segurança.
\end{abstract}

Palavras-chave: Amazônia Azul; Brasil; Soberania; Informação; Cooperação.

\begin{abstract}
The Blue Amazon is an important area under the responsibility of Brazil, it is an important reserve of natural resources. In the current geopolitical context there are threats to the exercise of sovereignty and jurisdiction. In this sense, Brazilian Navy has developed and is implementing the SisGAAz, which can be more efficient and effective with the vessels of the National Merchant Marine, which intensifies the Brazilian presence in this region, allowing besides the imposition of sovereignty through exploration and presence, but increasing logistic through the flow of information for accuracy and concentration of available resources for naval defense and maintenance of security.
\end{abstract}

Key-words: Blue Amazon; Brazil; Sovereignty; Information; Cooperation. 


\section{INTRODUÇÃOO}

A Amazônia Azul é tema recorrente em discussões relacionadas à defesa, soberania, transporte marítimo e segurança nacionais. Muitas vezes, trazida a baila no desenvolvimento da Política de Defesa Nacional, especialmente ao que se relaciona com as fronteiras marítimas, delineadas de acordo com a Convenção das Nações Unidas sobre o Direito do Mar.

A grande área sob jurisdição brasileira, que chega a aproximadamente 4,5 milhões de quilômetros quadrados, configura-se como um grande desafio logístico às atividades econômicas exploratórias lá desenvolvidas, assim como às atividades de defesa, segurança, monitoramento e controle, trazendo à Autoridade Marítima o desafio de desenvolver tecnologias para aprimorar os sistemas utilizados, a fim de gerar as redundâncias necessárias para garantir precisão e, por conseguinte, direcionar de forma mais eficiente os esforços logísticos dos recursos navais.

É nesse contexto que se insere a Marinha Mercante Brasileira, a qual através de sua atividade cooperativa, sendo "fiel parceira das forças armadas" e reserva da Marinha do Brasil, para fins de mobilização, podendo gerar real aprimoramento no ganho de informações precisas, se aliadas indissociavelmente do fortalecimento da Indústria Naval e do Ensino Profissional Marítimo.

Essa publicação busca analisar o desenvolvimento logístico que se pode obter a partir do fortalecimento de uma Marinha Mercante própria bem consolidada, tendo em vista a importância da Amazônia Azul para o desenvolvimento da soberania nacional, não alienando dos vieses sociais e econômicos para uma política de Estado de fortalecimento e crescimento nacional.

\section{DISPOSIÇÕES GERAIS CONCEITUAÇÃO DA AMAZÔNIA AZUL, DEFESA E LOGÍSTICA}

Os mares e oceanos têm sido importantes vias e fontes de desenvolvimento e riqueza para as nações que foram capazes de compreender e administrar as potencialidades disponíveis nessas áreas, e mesmo quando não ambicionados para expansão, foram e são imprescindíveis para o sustento e sobrevivência de populações menos voltadas para economia de mercado. Portugal, Inglaterra, Espanha, Holanda, entre vários outros vislumbraram esse potencial disponível e, dentro de seu contexto histórico, fizeram-se grandes. Surge, portanto, daí um secular conceito inglês: "onde houver um país que faça margem ao Oceano, esse país faz fronteira com Inglaterra”. Retoma-se, pois, a grande importância não só econômica, mas social, política, logística, ambiental, militar dessa grande massa líquida que em grande parcela cobre o planeta Terra.

Com o desenvolvimento de tecnologias, foi possível a descoberta no subsolo, solo e águas recursos naturais necessários à humanidade. Isso denota a tendência de que o mar continuará a ser importante para o futuro do mundo, pois além do transporte marítimo em escala mundial, o mar provê bens naturais e minerais em quantidade. É possível inclusive afirmar que no futuro essa importância será ainda maior, como consequência do crescimento dos recursos que vêm, cada vez mais, sendo colocados à disposição, enquanto em terra firme já demonstram sinais de escassez. (TILL, 2006, p.8) 
É nesse contexto de descobertas de reservas de recursos naturais e crescimento da importância econômica e geopolítica dos mares que se insere a Convenção das Nações Unidas sobre o Direito do Mar, realizada em 1982, na Jamaica. A partir da assinatura do documento nascido dessa discussão internacional, são estabelecidos os conceitos e limites do Mar Territorial, Zona Contígua e Zona Econômica Exclusiva; além de importantes definições no que diz respeito a direito de exploração e de exercício de soberania e jurisdição de países às margens dos mares sobre suas áreas de interesse.

O interesse brasileiro pelo mar é histórico e amplo, justificável ao passo que apresenta um litoral com extensão aproximada de 8,5 mil quilômetros. Pelo mar o Brasil foi colonizado e invadido, é por onde consolidou sua independência, é por onde ratifica diariamente a sua soberania e por onde realiza a maior parte de seu comércio. É dentro de toda essa conjuntura que se insere um conceito contemporaneamente muito discutido, sobretudo, a fim de desenvolver uma Consciência Situacional Marítima: Amazônia Azul. "Há outra Amazônia, cuja existência é, ainda, tão ignorada por boa parte dos brasileiros quanto foi aquela por muitos séculos. Trata-se da Amazônia Azul que maior que a verde, é inimaginavelmente rica. 3 Seria, por todas as razões, conveniente que dela cuidássemos antes de perceber-lhe as ameaças." Assim afirmou o Almirante-de-Esquadra Roberto de Guimarães Carvalho, então comandante da Marinha, em um artigo de sua autoria para a Folha de São Paulo. A Amazônia Azul é, em cumprimento à Convenção das Nações Unidas sobre os Direitos do Mar (CNDUM), que entrou em vigor no ano de 1994, uma área composta por doze milhas de Mar Territorial (contadas a partir da linha da costa) sobre o qual o Estado exerce "soberania plena em relação às águas, solo, subsolo e espaço aéreo sobrejacente"; doze milhas de Zona Contígua, que se superpõe à Zona Econômica Exclusiva, por uma extensão de 188 milhas (a partir do limite do Mar Territorial), onde o Estado não mais exerce soberania plena, mas tem jurisdição e exclusividade para fins de exploração e aproveitamento, conservação e gestão dos recursos naturais vivos e não-vivos das águas, do solo e do subsolo marinhos, para exploração e aproveitamento econômico e jurisdição, no que se refere à instalação e utilização de ilhas artificiais, instalações e estruturas (plataformas de petróleo, por exemplo), investigação científica marinha e proteção e preservação do meio marinho. Além das áreas já convencionadas, a Marinha do Brasil, a Petrobrás e a comunidade científica, realiza um projeto conhecido como LEPLAC (Levantamento da Plataforma Continental), consistindo em um estudo dirigido sobre os recursos disponíveis nessa área a fim de poder junto à Comissão de Levantamento da Plataforma Continental (CLPC) da ONU requisitar a extensão do limite exterior para além das duzentas milhas marítimas, em consonância com a parte VI da CNUDM.

O desenvolvimento nacional foi e continuará sendo dependente, em sua maior parte, do mar. Em função disso, a Política Nacional de Defesa torna prioritárias as áreas vitais, as quais são aquelas onde existe concentração de poderes político e econômico. No Brasil, 90\% do petróleo é produzido no mar, o restante é produzido em, sua maioria, em áreas costeiras, ou seja, próximas ao mar. Cerca de $80 \%$ da população concentra-se em uma faixa de duzentos quilômetros do litoral, ao alcance de ações incursionadas pelo mar. Isto é, há uma concentração de macrovalores ao alcance de ações vindas do mar. A Amazônia Azul é, portanto, um área vital. Os 4,5 milhões de quilômetros quadrados que integram a Amazônia Azul geram, pois, um grande desafio para vigilância, dificuldades essas incrementadas pelo avanço científico e tecnológico das formas de prospecção de petróleo, pela atividade 
pesqueira clandestina, pela escassez de recursos em outros países e pelas riquezas ainda desconhecidas.

A responsabilidade nacional da defesa da Amazônia Azul é incumbência da Marinha do Brasil, a qual necessita ter à disposição um poder naval forte, balanceado e compatível com a grandiosidade da imensa área marítima. Defesa é a ação efetiva para obter o grau de segurança desejado, sendo segurança a condição em que o Estado, a sociedade ou os indivíduos não se sentem expostos a riscos ou ameaças; as medidas de defesa são de largo espectro: defesa externa, defesa civil, políticas educacionais e ambientais, estando o conceito de segurança ampliado abrangendo os campos políticos, militar, econômico e social. Toda riqueza acaba por se tornar objeto de cobiça, cabendo ao detentor o ônus da proteção. É dever sagrado para a atual geração conhecer e desenvolver as capacidades necessárias para o pleno exercício sobre a Zona Econômica Exclusiva e a Plataforma Continental, que cabem pelos tratados internacionais vigentes (VIDIGAL, et al, 2009, p.15).

$\mathrm{O}$ intenso processo de globalização da contemporaneidade acabou por gerar um meio técnico-científico-informacional, altamente mutável e que transformou a tarefa da defesa, enquanto política de estado, uma tarefa difícil, constante, crescente e permanente. A Informação é chave primordial para eficiência e eficácia de qualquer ação para esse fim. Um 4 conceito moderno e extremamente necessário para compreensão do atual contexto geopolítico e econômico do país é Logística, que consiste, grosso modo, na gestão responsável, eficiente e eficaz da provisão de recursos, equipamentos e informação para execução da atividade desejada. Não se deve ater-se somente à distribuição de mercadorias, mas num contexto de ações de segurança, não a fim de assumir uma posição beligerante, para manutenção de ações pacíficas, uma vez que é preciso ser forte para ser pacífico, pensar na logística como algo inalienável das discussões a respeito da Amazônia Azul, em especial ao que diz respeito aos recursos humanos e materiais para garantia da obtenção de um fluxo de informações precisas constante, é fundamental.

\section{DESAFIOS LOGÍSTICOS E AMEAÇAS À AMAZÔNIA AZUL}

"É natural todo e qualquer país que tenha tráfego robusto, caso do Brasil, China, ter obrigação de proteger seu tráfego marítimo", afirma o Contra-Almirante Flávio Augusto Viana Rocha, Subchefe de Estratégia do Estado Maior da Armada do Brasil. A Amazônia Azul é prioritariamente uma área do nosso interesse, independentemente de outros países estarem fazendo isso ou aquilo, especialmente por os Estados Unidos, por exemplo, não ser signatário da CNUDM e ser uma reserva de muita riqueza. "O Brasil não é um país que tenha inimigos, mas ele não pode descuidar de seus interesses e ninguém pode descuidar da sua própria defesa", defende o ex-ministro da Defesa, Celso Amorim.

Nesse sentido, Vidigal (1997) aponta no início do século XX, o Barão de Rio Branco acreditava ser essencial que o Brasil voltasse a se projetar na América do Sul como potência dominante e ocupasse no cenário internacional uma posição compatível com sua grandeza. A defesa da Amazônia Azul é a colocação geoestratégica brasileira no tocante a todas as suas vantagens, naturais e conquistadas, em sua posição, motivo de cobiça internacional.

A partir dos anos 1970, segundo Wanderlei Messias da Costa (2012), o mar veio ganhando crescente importância nas políticas de Estado brasileiras em razão das descobertas de petróleo offshore - que alavancou significativos avanços na área de ciência e tecnologia - e do crescimento do comércio exterior ( $90 \%$ realizado por via marítima); passou-se, então, a dar 
maior importância ao aproveitamento do potencial marítimo nacional em suas políticas estratégicas. Nos últimos dez anos, o Brasil tem passado por um despertar para esse assunto.

Deve-se considerar que a repercussão de um ambiente em que o número de conflitos vem crescendo nas últimas décadas. De acordo com Costa (2012, p.17), as chances de o Brasil se ver envolvido em diversos tipos de contendas aumentam, à medida que for se fazendo cada dia mais presente. Nas últimas décadas, o núcleo da produção petrolífera mundial se deslocou do mundo industrializado para o subdesenvolvido, provocando um descasamento geográfico entre centros produtores e países demandantes de energia. Em face do acirramento da disputa global por fontes minerais e energéticas e de crescente valorização do mar como nova fronteira exploratória de recursos naturais, o Atlântico Sul está voltando a se apresentar como uma área relevante no cenário geopolítico internacional.

O governo brasileiro prega a defesa do Atlântico Sul e o combate a crimes como a pirataria e o tráfico de drogas, mas se opõe ao desdobramento de forças de ataque nos oceanos, isso tudo por um prisma de defesa à soberania no mar territorial e jurisdição na ZEE visando à defesa da Amazônia Azul. Enquanto arrefece na costa da Somália, na costa oriental da África, a pirataria tem se agravado na margem ocidental do continente. 15 casos de pirataria na região no primeiro trimestre de 2013, dos quais 11 ocorreram na costa da Nigéria.

O desafio para consolidação das pretensões econômicas, políticas, sociais e militares brasileiras deve ser enfrentado. Dentre esses desafios é possível destacar a eventual cobiça 5 pelos recursos advindos da imensa área marítima conquistada com a assinatura e o cumprimento das regras definidas na CNUDM, no que tange ao mapeamento da plataforma continental. Não se pode deixar de mencionar os recorrentes exemplos de possíveis ameaças sofridas pelo Brasil em um contexto de projeção diplomática e geopolítica que foi a reativação da IV Frota, por parte da Marinha Americana, uma vez que, é demonstrada preocupação estratégico-militar de Washington para com a América do Sul e África Ocidental, o que os farão mais presentes no Atlântico Sul, despertando em muitos uma visão de desconfiança por uma possível ameaça à segurança na América do Sul e à soberania brasileira, em especial, em respeito à preservação da Amazônica Azul brasileira e todas as suas reservas de recursos naturais; o outro é a conhecida Guerra da Lagosta, resolvida por vias diplomáticas.

As possíveis intervenções por razões econômicas, respaldadas pelo "dever de ingerência", sob a capa de razões éticas, defesa da humanidade ou do meio ambiente, virão por via marítima. Para isso, não é lógico nem prudente descuidar-se dos diversos componentes do poder marítimo, e muito menos deixar de alocar à Marinha do Brasil os recursos e os meios imprescindíveis para que ela possa não só atuar na vigilância e na proteção desse imenso patrimônio, mas também honrar os compromissos internacionais, principalmente no momento histórico em que o país pretende ter voz no cenário mundial (CARVALHO, 2005, p.3). É importante se pensar em Amazônia Azul em sentido mais amplo, é comum se errar e pensar na porção produtora de petróleo somente; pensar num todo indivisível e planificado em importância é necessário para não se incorrer de incorporar recursos, onerando o erário público, com soluções e desenvolvimentos logísticos que gerarão sombras e pontos de fraqueza no monitoramento e obtenção de informações não precisas tornando-se algo ineficaz. É importante, pois, acompanhar, monitorar, e quando necessário, controlar, o tráfego marítimo das águas jurisdicionais brasileiras, mas mais ainda do seu entorno, o Atlântico Sul. 


\section{MARINHA MERCANTE: FORTALECIMENTO LOGÍSTICO NA DEFESA DA AMAZÔNIA AZUL}

O Poder Nacional é definido como a capacidade que tem o conjunto de homens e dos meios que constituem a Nação, atuando em conformidade com a vontade Nacional, de alcançar e manter os objetivos nacionais (Constituição Federal, 1988, art. $3^{\circ}$ ). O resultado da integração dos recursos disponíveis por uma nação para utilização do mar e das águas interiores, seja como ferramenta de ação política e militar, seja como instrumento de desenvolvimento econômico e social, visando à conquista e à manutenção dos objetivos nacionais, configura o que é definido como Poder Marítimo (Defesa, 2007). O qual, por sua vez, engloba o Poder Naval, a indústria nacional de defesa, os portos nacionais e sua infraestrutura, a indústria naval, a Marinha Mercante, e, considerada como imprescindível a todo esse conjunto, a mentalidade situacional marítima ou, simplesmente, consciência marítima.

A delimitação e defesa das fronteiras em terra firme, quando não existe obstáculo natural (montanhas, rios, depressões) ou artificial (muros ou cercas) se configura como tarefa árdua; todavia, quando se pensa nas demarcações sobre uma massa fluída, que é o mar, estabelecidas de modo ainda mais imaginário e virtual a missão é ainda mais dificultada. É de ciência comum a importância do transporte marítimo de cargas para o desenvolvimento econômico do país, sendo a via marítima o meio pelo qual é transportada a maior parte das importações e exportações. Esse é um papel pertencente à Marinha Mercante.

A vigilância, controle e monitoramento do tráfego marítimo e atividades realizadas na Amazônia Azul são bem complexos devido à logística necessária em função da grande extensão dessa área vital. Apesar da vultosa incumbência da Marinha do Brasil, o Brasil não se posiciona como uma potência marítima, embora disponha de equipamentos suficientes para o desenvolvimento das missões nas águas jurisdicionais (PENHA, 2012, p. 126). Entretanto, não se pode desconsiderar que, como mencionado anteriormente, o mar é um enorme palco de disputas, indo além, ao se considerar o volume de mercadorias transportadas, o modal aquaviário é, pois, fundamental na manutenção da segurança nacional. Entra, portanto, como figura fortalecedora de defesa da soberania a Marinha Mercante.

A Marinha Mercante é uma alternativa para auxiliar na defesa marítima do país, em especial no patrulhamento e na troca de informações, não havendo desvirtuação das reais funções da Marinha Mercante brasileira. A cooperação entre a Marinha Mercante Brasileira e a Marinha do Brasil possibilitaria além do desenvolvimento da exploração das riquezas um sentimento nacionalista de posse da Amazônia Azul, como a ocupação de fato da mesma (CACALCANTE, 2010).

Conforme menciona Vidigal (2005), durante a Guerra das Malvinas, em 1982, e Guerra do Golfo, 1980, houve intensa utilização, por parte dos países envolvidos, dos navios mercantes como apoio aos navios de guerra, principalmente no fluxo logístico. Sendo, pois, esse apoio ao fluxo logístico, em especial ao fornecimento de dados e informações que é defendido.

Já sendo os navios mercantes pontos de monitoramento e fornecimento de informações de diversos sistemas de monitoramento da Marinha do Brasil - SISTRAM, SIMMAP; SisGAAz, em implantação, por exemplo -, é imperiosa a necessidade de se fortalecer a frota de navios mercantes. A maior parte dos navios em circulação nas águas 
jurisdicionais brasileiras possui bandeira estrangeira. Uma Marinha Mercante Brasileira própria é primordial para a defesa da soberania nacional sobre a Amazônia Azul.

A cooperação entre a Marinha do Brasil e Marinha Mercante é, pois, vital para o desenvolvimento logístico necessário para alcançar a eficiência e aumentar a eficácia do monitoramento da Amazônia Azul. É determinante a assunção de duas posturas para obtenção esse fortalecimento logístico: a consolidação da Indústria Naval e o aprimoramento do Ensino Profissional Marítimo.

Uma Indústria Naval forte é logicamente um fator primordial, denotando autonomia da nação na detenção da tecnologia de construção e manutenção dos meios navais necessários, o que é ainda mais relevante quando pensado nesse como um setor estratégico de segurança nacional.

O Ensino Profissional Marítimo é hoje de responsabilidade da Autoridade Marítima; tripulações brasileiras cada vez mais qualificadas e conhecedoras de suas funções e detentoras de uma consciência marítima bem formada são primordiais para a garantia do bom serviço, segurança da navegação e segurança nacional. Especificamente, em relação à formação dos oficias da Marinha Mercante, é feita, principalmente, nas Escolas de Formação de Oficiais da Marinha Mercante do Centro de Instrução Almirante Braz de Aguiar e do Centro de Instrução Almirante Graça Aranha, em Belém e no Rio de Janeiro, respectivamente. De acordo com o Estatuto dos Militares, aqueles que integram a Marinha Mercante são, para efeito de mobilização, reserva da Marinha do Brasil, em função disso os Oficias da Marinha Mercante formados nas instituições supramencionadas recebem Formação Militar Naval. Portanto, isso pressupõe uma cooperação já existente, devendo ser estendida e aprimorada no exercício da tarefa propriamente dita. $\mathrm{O}$ constante, crescente e permanente investimento na melhoria da 7 formação e qualificação desses profissionais é necessário para permitir melhor desempenho no serviço e fornecimento de informações mais precisas para os sistemas de monitoramento.

Conforme afirma o diplomata e ex-ministro da defesa Celso Amorim, "a Defesa Nacional, será tão mais robusta quanto mais contar com a sociedade; ela não pode legitimar os seus pleitos, a não ser por meio da compreensão, por parte da sociedade, das necessidades que tem o Brasil"”.

\section{SISGAAZ}

O Sistema de Gerenciamento da Amazônia Azul (SisGAAz) é concebido em função da escassez de recursos disponíveis, defesa, fiscalização e monitoramento da Amazônia Azul que acontecem de forma limitada e comprometida. A grande missão desse sistema é monitorar e controlar de forma integrada as águas jurisdicionais brasileiras, a região SAR de responsabilidade do Brasil e as demais áreas de interesse estratégico. (ROBERTO, 2012). O SisGAAz divide-se em Sistema de Monitoramento da Amazônia Azul - prevenção e controle e o Sistema de Proteção da Amazônia Azul - reação e defesa. O sistema funciona por meio de sensores e sistemas específicos, permitindo a coleta de dados, fusão e processamento destes, produção de informação para apoio à decisão e, por fim, a tomada de decisão para atuação dos meio disponíveis (ÖBERG, 2011 apud MALSCHITZKY, 2011). Dentre outras possibilidades a implantação do sistema permitirá a incrementação da:

- antecipação da detecção e identificação de ameaças, permitindo maior tempo para decisão e reação;

- redução ou eliminação dos efeitos incidentes que venham a poluir o ambiente marinho; 
- segurança da navegação;

- garantia da salvaguarda da vida humana no mar.

O SisGAAz continuará a receber dados oriundos do SIR (Sistema Integrado de Radiogoniometria), SMM, SAETE e SISTRAM (Sistema de Informação sobre o Tráfego Marítimo), que por sua vez é alimentado por dados do AIS (Automatic Identification System), LRIT (Long Range Identification and Tracking), SIMMAP (Sistema de Monitoramento Marítimo de Apoio às Atividades de Petróleo), PREPS (Programa de Rastreamento de Embarcações Pesqueiras por Satélite), VRMTC (Virtual Regional Maritime Traffic Centre), CNIES (Cooperative Nations Information Exchange System) e MSSIS (Maritime Safety and Security Information System), além de informações recebidas de navios da MB, aeronaves da MB e da FAB (Força Aérea Brasileira), navios mercantes, Petrobrás e mensagens padronizadas de organizações terrestres da MB (Capitanias, Delegacias, Agências). Incorporando também dados de outros sistemas provedores como o Sistema de Tráfego de Embarcações, radares de longo alcance, Sensoriamento Remoto por Satélite, sensores acústicos submarinos, Veículos Aéreos não Tripulados e Blimps (Balões de grande porte, com formato semelhante a dirigíveis). Vê-se que são muitos sistemas sendo integrados a fim de fornecer dados que gerem a redundância necessária para a garantia da precisão à informação.

Mesmo com todo o refino tecnológico presente no SisGAAz contribuindo para a fortalecimento de uma Consciência Situacional Marítima, é imprescindível que ela seja consolidada e aliada aos recursos necessários para permitir as tomadas de decisão em favor desse gigante patrimônio nacional. A ideia de controle é primordial, não se pode comparar a atuação jurisdicional sobre terra, que se mantém embebida nos princípios de exercício da soberania permitindo uma físcalização ostensiva. Sob a massa fluída oceânica são conceitos 8 que, em determinados momentos, se mantém díspares, conforme versa a legislação internacional, da qual o Brasil é signatário, sobre os direitos de Passagem Inocente, Direito de Visita, Perseguição, o exercício do poder marítimo sobre mar territorial e águas jurisdicionais, dentre outros que limitam a abordagem e mudam a natureza do que se concebe como o controle.

A Doutrina Básica da Marinha conceitua o controle de área marítima, como certo grau de garantia de utilização, ainda que temporária, de áreas marítimas limitadas, estacionárias ou móveis, exercido na intensidade adequada à execução de atividades específicas (BRASIL, 2004). A soberania nas áreas marítimas é garantida pela disponibilidade de navios de superfície, aeronaves e sistemas de monitoramento; a representação dessa presença do Estado no mar se dá por embarcações que arvorem a bandeira nacional, não somente navios de guerra, mas também navios mercantes, não constituindo isso em um desvirtuamento das reais funções dessas embarcações.

Os navios mercantes brasileiros podem funcionar como reais balizadores, pontos de monitoramento, e por que não, vigilância das águas jurisdicionais, permitindo assim com a devida aplicação, qualificação, especificação a concentração e canalização dos meios navais de proteção, defesa e reação nos pontos de maior necessidade. Para isso, é importante, é estratégico, é uma questão de segurança nacional, é um fortalecimento logístico no fluxo de informação e melhoria na eficiência e empregos dos recursos navais na defesa e proteção da soberania e jurisdição sobre a Amazônia Azul, a consolidação de uma Marinha Mercante Nacional Própria engajada no exercício de monitoramento do patrimônio Nacional e com uma Consciência Marítima Consolidada. 


\section{CONSOLIDAÇÃO DA MARINHA MERCANTE NACIONAL: FORTALECIMENTO LOGÍSTICO}

O investimento e a busca pela consolidação de uma Marinha Mercante permanente no Brasil, como visto, despertará um desenvolvimento logístico que melhorará a eficiência no emprego dos recursos navais a fim de defender a soberania sobre a Amazônia Azul. Todavia, prender-se somente a esse aprimoramento no fluxo de informações, a fim de fornecer dados mais precisos aos sistemas de monitoramento e controle, seria superficial. Uma Marinha Mercante própria gerará, invariavelmente, o avanço na qualidade dos serviços de transporte marítimo; reativando, restaurando e criando novas vias de fluxo de mercadorias, acentuando a utilização do modal marítimo como solução logística ao transporte de cargas em mar territorial brasileiro em detrimento do modal rodoviário, como matriz capital, atendendo às necessidades das cidades costeiras, nas quais está concentrada, aproximadamente, $80 \%$ da população. É, pois, questão de interesse estratégico o fortalecimento da marinha mercantes nacional, como forma de assegurar a participação no mercado mundial de transporte de bens e serviços e o desenvolvimento da atividade de transporte marítimo.

Em comparação à Marinha Mercante Brasileira das décadas de 50, 60 e 70, período que podemos chamar de "belle èpoque" desse setor aqui no país, a atual frota navega a passos muito pequenos, com linhas de Longo Curso muito insipientes, e cabotagem também realizada por navios de bandeiras estrangeiras. Entretanto, não se pode cometer anacronismo e deixar de lado a situação atual, com um mercado distinto, com tendências diferentes, e, devido ao intenso processo de globalização e desenvolvimento, do já citado, meio técnicocientífico-informacional, a internacionalização do transporte marítimo, nem tampouco inferir 9 que o fortalecimento da indústria naval brasileira será um entrave a esse processo, mas um fortalecimento doméstico projetado ao âmbito internacional.

A presença da Bandeira Nacional arvorada nos navios mercantes, em especial no MT e ZEE, é fator decisivo para "materialização" da presença brasileira nas águas pertencentes à nação. Todavia, políticas de Estado devem ser adotadas para incentivar o crescimento desse setor. São tendências na gestão dos transportes marítimos a integração e cooperação dos operadores marítimos com portos, terminais portuários e demais serviços complementares, demandando, pois, a modernização dos portos; a atenção redobrada sobre a formação de custos (competitividade com as Bandeiras de Conveniência- BDC); apelo ao apoio do Estado para compensar sobrecustos por uso da bandeira.

É, inclusive, orientação da Comissão da Comunidades Europeias para a política de transporte marítimo para 2018, a manutenção e, se necessário, reforço à luz da experiência adquirida com a replicação das orientações para os auxílios estatais no setor do transporte marítimo, um enquadramento claro e competitivo para a tributação. Assim, deve fazer parte da política de Estado a busca por assegurar a competitividade das frotas nacionais no mercado global, incentivando o registro nacional, evitando a saída das embarcações para as bandeiras de conveniência e manter a qualidade do trabalho marítimo e proteger o marítimo nacional. Dessa forma desenvolvendo em sua plenitude a consciência situacional marítima

É indissociável, e inevitável, apontar para a importância da formação do marítimo/ aquaviário, para assim permitir uma condução segura e eficaz do exercício do comércio marítimo e, por conseguinte, uma presença eficiente da frota nacional em questões de segurança nacional. Por isso, o Ensino Profíssional Marítimo não deve ser negligenciado em 
nenhum de seus âmbitos, aprimorando e incluindo novas tecnologias, metodologias e processos, assim como, mantendo as tradições e cultura marinheiras, a exemplo de excelentes espelhos que são algumas das nações europeias, tais como a Dinamarca e Noruega.

Os Estados Nacionais devem proteger os segmentos estratégicos da competição internacional, por meio de políticas e subsídios e da reserva de mercado. A Atividade Marítima e inalienável daquilo que hoje chamamos de economia e política nacional, portanto, é um setor estratégico, sobremodo o segmento chamado de navegação de cabotagem. A reserva de mercado na navegação de cabotagem é praticada por diversos países com tradição marítima, com o objetivo de preservar a frota própria, controlar e regular o mercado doméstico da navegação. De acordo com o Levantamento do Departamento Americano de Transporte, citado na Avaliação da Política Marítima do EUA para os próximos 30 anos, a adoção de políticas para proteger, e para o caso do Brasil, consolidar a sua Marinha Mercante Nacional, deve objetivar o desenvolvimento da própria marinha mercante, valorizar o trabalho e a indústria nacional, gerar empregos, apoiar a segurança nacional e proteger a economia doméstica. Como resultado desse levantamento realizado com 56 nações, tem-se que: 44 delas têm sua cabotagem restrita a navios nacionais; 17 aplicam subsídios a favor da frota nacional; 13 aplicam subsídios indiretos; 43 aplicam restrições sobre a composição das tripulações; 32 aplicam restrições sobre a propriedade das embarcações. Esse levantamento aponta, ainda, que os países que se destacam internacionalmente com suas frotas aplicam subsídios da construção, têm programas de financiamento a essa indústria, realizam tratamento fiscal diferenciado, programas sociais e econômicos, auxílio à construção e sucateamento, depreciação de taxas especiais, subsídios operacionais, reserva de carga prescrita, empresas de navegação governamental.

Dessa forma, é notória a responsabilidade governamental na promoção de uma Marinha Mercante própria por questões de defesa e soberania, como fora mencionado 10 anteriormente, e também por questões de fortalecimento logístico a fim de tornar mais eficiente e eficaz o transporte marítimo, não podendo negligenciar os setores subsidiários desse fortalecimento, tais como, a Indústria Naval e o Ensino Profissional Marítimo.

\section{CONSIDERAÇÕES FINAIS}

O Brasil, não diferente das nações que margeiam os oceano e mares, tem nessas áreas importante fonte de recursos naturais e vias de fluxo de transportes e bens. Em consonância com a Convenção das Nações Unidas sobre o Direito do Mar, o Brasil tem hoje uma área de águas jurisdicionais de 4,5 milhões de quilômetros quadrados. E como visto, isso se configura como um desafio gigantesco para o controle, monitoramento, segurança e defesa dessa região.

Os inúmeros recursos naturais disponíveis despertam o interesse estrangeiro. A partir disso entra a concepção da Política de Defesa Nacional, que versa sobre a defesa e segurança, assim como, o exercício da soberania e jurisdição, restringindo à discussão desenvolvida, às áreas marítimas de interesse brasileiro.

Para contornar o desafio de monitoramento de extensa área, a Marinha do Brasil desenvolveu e está implantando o Sistema de Gerenciamento da Amazônia Azul objetivando monitorar e controlar de forma integrada as águas jurisdicionais brasileiras, a região SAR de responsabilidade do Brasil e as demais áreas de interesse estratégico, recebendo intenso fluxo de dados a fim de gerar a redundância necessária para garantir precisão à informação e tornar mais eficiente o emprego dos recursos navais de defesa. 
Na obtenção de dados se considera como importantes ferramentas cooperadoras os navios mercantes brasileiros, os quais podem funcionar como reais balizadores, pontos de monitoramento, e por que não, vigilância das águas jurisdicionais, permitindo assim com a devida aplicação, qualificação, especificação a concentração e canalização dos meios navais de proteção, defesa e reação nos pontos de maior necessidade, sem desvirtuar a real função desses navios.

Dessa forma é imperioso afirmar a necessidade de políticas de Estado a fim de fortalece a Marinha Mercante Nacional e as suas "subsidiárias" a Indústria Naval e o Ensino Profissional Marítimo, fazendo todo esforço legislativo e financeiro para a garantia dessa importante ferramenta econômica, logística e de defesa da soberania, a qual é exercida pela bandeira brasileira arvorada nos mastros dos navios mercantes nacionais.

\section{REFERÊNCIAS}

[1] ABREU, Guilherme Matos de. Almirante. A Amazônia Azul: O Mar que nos Pertence. 2010

[2] BARBOSA, Murillo de Moraes Rego Corrêa. A Marinha Mercante Brasileira - Desafios e a participação do Estado no seu Desenvolvimento. Agência Nacional de Transporte Aquaviários. Rio de Janeiro, 2000.

[3] BONFIM, Uraci Castro.Curso de Política, Estratégia e Alta Administração do Exército. Escola do Estado-Maior do Exército. Rio de Janeiro, 2005

[4] BRASIL, Ministério da Defesa. Amazônia Azul: Ameaças. Ministério da Defesa. Disponível em < http://www.defesabr.com/MD/md_amazonia_azul.htm> Acesso em 07 de fevereiro de 2015. 11

[5] CHAVES, Sergio Fernando de Amaral Junior. Sistema de Gerenciamento da Amazônia Azul: O passo inicial para o efetivo controle da área marítima brasileira. Escola Superior de Guerra. Rio de Janeiro, 2013.

[6] FERREIRA, Helena Lucia Damasceno; BARBOSA, Victor Resque de Barros; MIRALHA, Waldir Carlos da Silva. Marinha Mercante Brasileira Atuando como Parceira na Segurança Nacional: perspectivas de cooperação na Amazônia Azul. Centro de Instrução Almirante Braz de Aguiar. Belém, Pará, 2013.

[7] MATSUMOTO, Cássio Hatsumi; SILVA, Messias Bezerra da Neto; LIMA, Rui Barbosa Net; FERREIRA, Helena Lucia Damasceno Ferreira. A Soberania Brasileira sobre o pré-sal: A utilização plena dos recursos oriundos da Amazônia Azul e sua Logística de Transporte. Centro de Instrução Almirante Braz de Aguiar. XVII Simpósio de Pesquisa Operacional e Logística da Marinha. Belém, Pará, 2014.

[8] SILVA, Eliomar Divino. Amazônia Azul: uma realidade geopolítica brasileira. Revista Eletrônica Tempo Presente. Disponível em: http://www.tempopresente.org/index.php?option=com_content\&view=article\&id=5210:amaz onia-azul-uma-realidade-geopolitica-brasileira\&catid=38\&Itemid=127> Acesso em 07 de fevereiro de 2015.

[9] TAYLOR, Paul D. Perspectivas sobre Estratégia Marítima. Naval War College Press. Newport, 2009. 